\title{
Can prostaglandin E1 (Misoprostol) be an alternative to prostaglandin E2 (PGE2) for induction of labor in prelabor rupture of membranes (PROM) after 34 weeks period of gestation
}

\author{
Jitendra D. Mane*, Anil K. Singh
}

Department of Obstetrics and Gynecology, Military Hospital, Dehradun, Uttarakhand, India

Received: 19 August 2017

Accepted: 23 August 2017

\section{*Correspondence:}

Dr. Jitendra D. Mane,

E-mail: jitendra.mane@yahoo.com

Copyright: () the author(s), publisher and licensee Medip Academy. This is an open-access article distributed under the terms of the Creative Commons Attribution Non-Commercial License, which permits unrestricted non-commercial use, distribution, and reproduction in any medium, provided the original work is properly cited.

\begin{abstract}
Background: To compare efficacy and safety of prostaglandin E1 (misoprostol) to prostaglandin E2 (PGE2) for induction of labor in prelabor rupture of membranes (PROM) after 34 weeks period of gestation and its use as an alternative to PGE1.

Methods: 80 women were recruited in this prospective interventional study who was admitted with PROM after 34 weeks of period of gestation for delivery. These women who were planned for induction of labor were alternately assign into two groups i.e. Misoprostol group $(\mathrm{n}=40)$ who received Tab misoprostol 50 mcg orally 4 hourly $(\mathrm{h})$ maximum of five doses and PGE2 group $(n=40)$ received PGE2 gel intracervically every $6 \mathrm{~h}$ for maximum of 3 doses. Analysis regarding safety and efficacy of the drugs was done with regards to maternal and perinatal outcome.

Results: Out of 80 women, 40 received misoprostol and 40 received PGE2 gel. The intervention to induction interval was significantly less in PGE2 group (p-0.004) whereas the induction to delivery interval was similar in both groups (p- 0.628). Significant number of women delivered vaginally without need for oxytocin in misoprostol group, (p0.039) however there was no statistical difference in both groups as far as overall vaginal deliveries and caesarean section are concerned. Comparable neonatal and maternal morbidities were noted in both groups.

Conclusions: Oral misoprostol can be used as an alternative to PGE2 gel for induction of labor after 34 weeks of period of gestation in women with PROM as it was found to be safe and effective in achieving vaginal deliveries with reduced need for oxytocin, without increasing maternal and neonatal morbidity.
\end{abstract}

Keywords: Beyond 34 weeks period of gestation of pregnancy, Induction of labor, PGE1(Misoprostol), PGE2 gel, PROM

\section{INTRODUCTION}

$5-10 \%$ of all pregnant women have premature rupture of membranes (PROM) of this around $60 \%$ occurs at term. PROM is associated with numerous maternal and neonatal complications like infections, cord prolapse, low Apgar score at five minute and operative deliveries. ${ }^{1}$ The etiology and pathophysiology of PROM is obscure and hence opinion regarding management of this disorder varies widely. ${ }^{2}$ Prelabor rupture of membranes is also associated with chorioamnionitis in $6-10 \%$ of women at term and up to $40 \%$ in women with membranes ruptured for more than 24 hours.

Induction of labor is the only strategy besides expectant management for PROM after 34 weeks of period of gestation that reduces the infectious morbidity for both mother and infant. Women managed expectantly will go 
into spontaneous labor and delivery within 24, 48 and 72 hours of PROM in 70, 85 and 95 per cent of cases, respectively. ${ }^{3}$ However neonatal risks of expectant management include infections $(2.8 \%)$, admission to intensive care unit $(8 \%)$, placental abruption, fetal distress $(2 \%)$, fetal restriction deformities, pulmonary hypoplasia and neonatal death $(1 \%) .{ }^{4}$ Hence obstetricians find it necessary to manage PROM patients actively to avoid complications to both mother and child. ${ }^{5}$

Various agent helps to stimulate uterine contractions and cause cervical ripening and dilatation amongst these prostaglandins are one of them. Prostaglandins act on uterus by increasing the calcium influx and modulating the c- AMP along with collagen breakdown and dispersal in cervical tissue leading to uterine contractions and cervical dilatation. The success depends on the dose of prostaglandin, site of administration, condition of the cervix at the time of induction and parity. Prostaglandins are found beneficial in induction of labor in women having unfavourable cervix along with reduction of caesarean sections. ${ }^{6}$

PGE2 gel is an accepted modality for preinduction cervical ripening and induction of labor but with some limitation of expertise for instillation of gel, require refrigeration for storage and cost. Misoprostol is another prostaglandin which can be used for induction of labor with added advantage of ease of administration, storage in room temperature and less costly then PGE2 gel. Few studies are available for induction of labor in setting of PROM comparing PGE1 to misoprostol, hence undertaken this study. ${ }^{7}$ Tab misoprostol $50 \mathrm{mcg}$ orally was selected, the dose which was recommended and found safe for induction. ${ }^{7,8}$ Oral routes for administration of drug was preferred as women enrolled are with PROM to reduce the need for repeated vaginal examinations and chances of ascending infections.

\section{METHODS}

A prospective interventional study was conducted at 500 bedded zonal government hospital. The study was performed from Sep 2015 to Dec 2016. Institutional ethical committee's clearance was taken prior to commencement of the study. The inclusion criteria included women with PROM $>6 \mathrm{~h}$ at term, preterm PROM after achieving fetal lung maturation, singleton pregnancy, cephalic presentation, reactive non-stress test, not in labor, liquor clear, no contraindication to vaginal birth, bishop score <6. Exclusion criteria were women with previous caesarean pregnancy, multiple pregnancies, meconium stained liquor, glaucoma, bronchial asthma, unexplained vaginal bleeding and malpresentation.

After admission, through history, clinical examination and perusal of antenatal documents was done to confirm period of gestation, presence of PROM, and no other complications were present. Complete blood count, urine routine with microscopy along with culture, vaginal swab for culture and antibiotics sensitivity was sent. All women were given injectable antibiotics. Written and informed consent was taken from all women and their relatives. 80 women were enrolled in the study who were placed into two group's i.e. Misoprostol and PGE2 group alternately. In misoprostol group $(n=40)$ women were induced with tab misoprostol $50 \mathrm{mcg}$ orally every $4 \mathrm{~h}$ with maximum of 5 doses if needed. $100 \mathrm{mcg}$ squared tablet was divided into two to get $50 \mathrm{mcg}$ of misoprostol. In PGE2 group $(\mathrm{n}=40)$ women were induced with $0.5 \mathrm{mg}$ PGE2 gel intracervical route under aseptic precaution and repeated at $6 \mathrm{~h}$ interval if needed for maximum 3 doses.

The women were assessed periodically for uterine contractions, fetal wellbeing by cardiotocographic monitoring and cervical status. Oxytocin was used to induce or augment labor after $4 \mathrm{~h}$ of last dose of misoprostol or $6 \mathrm{~h}$ of last dose of PGE2 gel and further dosages of misoprostol or PGE2 gel were omitted. Women with Bishop's score $<6$ after completing the full course of medication, unsatisfactory progress of labor or abnormal fetal heart rate pattern suggesting fetal distress, were taken up for caesarean section. Women were monitored for occurrence of hyperstimulation and tachysystole and managed accordingly.

The efficacy of misoprostol was compared to PGE2 gel on the basis of intervention (use of either of prostaglandins for labor induction) to induction interval, induction to delivery interval, need of oxytocin for augmentation or induction of labor, and rate of vaginal delivery along with caesarean section. Safety was evaluated by noting maternal and perinatal complications.

Mean and standard deviations were noted for continuous variables. Chi-square test, unpaired t test and fisher exact test was applied for statistical evaluation. The statistical significance was considered as $<0.05$.

\section{RESULTS}

Table 1: Characteristic of patients.

\begin{tabular}{|llll|}
\hline Characteristic & $\begin{array}{l}\text { Misoprostol } \\
\text { group } \\
(\mathrm{n}=40)\end{array}$ & $\begin{array}{l}\text { PGE2 } \\
\text { group } \\
(\mathrm{n}=40)\end{array}$ & $\begin{array}{l}\text { p } \\
\text { value }\end{array}$ \\
\hline $\begin{array}{l}\text { Mean Age } \\
\text { (mean } \pm \text { SD) }\end{array}$ & $25.03 \pm 3.25$ & $25.65 \pm 4.03$ & $0.521^{\#}$ \\
\hline $\begin{array}{l}\text { Mean Parity } \\
\text { (mean } \pm \text { SD) }\end{array}$ & $1.56 \pm 0.62$ & $1.46 \pm 0.57$ & $0.520^{\#}$ \\
\hline $\begin{array}{l}\text { Mean } \\
\text { gestational age } \\
\text { (mean } \pm \text { SD) }\end{array}$ & $37.30 \pm 1.92$ & $38.01 \pm 1.52$ & $0.777^{\#}$ \\
\hline $\begin{array}{l}34 \text { weeks to } 36 \\
+6 \text { weeks }(\%)\end{array}$ & $11(27.5 \%)$ & 9 & $(22.5 \%)$ \\
\hline $\begin{array}{l}37 \text { weeks and } \\
\text { beyond (\%) }\end{array}$ & $29(72.5 \%)$ & $\begin{array}{l}31 \\
(77.5 \%)\end{array}$ & \\
\hline $\begin{array}{l}\text { Mean Bishop's } \\
\text { score } \\
\text { (mean } \pm \text { SD) }\end{array}$ & $3.33 \pm 0.88$ & $2.93 \pm 0.82$ & $0.075^{\#}$ \\
\hline
\end{tabular}


Characteristics of study subjects with respect to their mean age, mean parity, mean gestational age was similar in both groups.

The period of gestation at which women with PROM were enrolled was similar i.e. $27.5 \%$ versus $22.5 \%$ from 34 weeks to $36+6$ weeks and $72.5 \%$ versus $77.5 \%$ from 37 weeks and beyond for misoprostol and PGE2 gel group. Similar distribution of women was present with regards to Bishop's score was concerned before intervention (Table 1).

Onset of PROM and intervention was variable depending on patients reporting to the hospital and period of gestation. Maximum number of women were actively managed within 6-12 h of onset of PROM i.e. twentynine $(72.50 \%)$ versus thirty-two $(80 \%)$ from misoprostol and PGE2 gel respectively.

Remaining women were induced in 12-24 h (8 versus 6) (p-0.773) and more than $24 \mathrm{~h}$ (3 versus 2) (p-0.99) from onset of PROM with similarity in both groups (Table 2).
Table 2: Onset of PROM to intervention interval.

\begin{tabular}{|llll|} 
Characteristic & $\begin{array}{l}\text { Misoprostol } \\
\text { group } \\
(\mathrm{n}=40)\end{array}$ & $\begin{array}{l}\text { PGE2 } \\
\text { group } \\
(\mathrm{n}=40)\end{array}$ & $\begin{array}{l}\text { P } \\
\text { value }\end{array}$ \\
\hline $6-12 \mathrm{~h}$ & $29(72.50)$ & $32(80 \%)$ & $0.772^{\# \#}$ \\
\hline $12-24 \mathrm{~h}$ & $8(20 \%)$ & $6(15 \%)$ & $0.773^{\$}$ \\
\hline$>24 \mathrm{~h}$ & $3(7.50 \%)$ & $2(5 \%)$ & $0.99^{\$}$ \\
\hline Total & 40 & 40 & \\
\hline
\end{tabular}

Interval between interventions to induction of labor with misoprostol was statistically slow then with PGE2 gel ( $p$ - 0.004) however the induction to delivery interval was same ( $\mathrm{p}-0.628)$. The need for oxytocin use for induction or augmentation in labor was much less in misoprostol group. Number of women achieving vaginal delivery thirty-five $(87.5 \%)$ versus thirty-three $(82.5 \%)$ and undergoing caesarean section five $(12.5 \%)$ versus seven (17.5\%) in misoprostol versus PGE2 gel group was similar. Duration of labor was comparable in both groups. Maternal complications were noted and were comparable. Only two women had hyperstimulation in misoprostol group (Table 3).

Table 3: Maternal effects.

\begin{tabular}{|c|c|c|c|}
\hline Characteristics & Misoprostol group $(n=40)$ & PGE2 group $(n=40)$ & p value \\
\hline Intervention to induction of labor $(\mathrm{h})($ mean $\pm \mathrm{SD})$ & $10.60 \pm 2.45$ & $9.24 \pm 2.16$ & $0.004^{\#}$ \\
\hline Induction of labor to delivery $(\mathrm{h})($ mean $\pm \mathrm{SD})$ & $6.8 \pm 1.09$ & $6.93 \pm 1.89$ & $0.628^{\#}$ \\
\hline Oxytocin use for induction/augmentation of labor & $11(27.5 \%)$ & $26(\%)$ & $0.039^{\# \#}$ \\
\hline Number of doses $($ mean $\pm \mathrm{SD})$ & $3.22 \pm 1.01$ & $1.98 \pm 0.54$ & \\
\hline Vaginal delivery & $35(87.5 \%)$ & $33(82.5 \%)$ & $0.858^{\# \#}$ \\
\hline Caesarean delivery & $5(12.5 \%)$ & $7(17.5 \%)$ & $0.758^{\$}$ \\
\hline Fetal distress & 3 & 2 & \\
\hline Failed induction & 1 & 2 & \\
\hline Non-progress of labor & 1 & 3 & \\
\hline Hyperstimulation & $2(5 \%)$ & 0 & \\
\hline
\end{tabular}

Even though the meconium stained liquor (12.5\% versus $7.5 \%)$ and NICU admissions (17.5\% versus 12.5$)$ were more in misoprostol group but it was not statistically significant (Table 4).

Table 4: Neonatal outcome.

\begin{tabular}{|llll|}
\hline Characteristic & $\begin{array}{l}\text { Misoprosto } \\
\text { Igroup } \\
(\mathrm{n}=40)\end{array}$ & $\begin{array}{l}\text { PGE2 } \\
\text { group } \\
(\mathrm{n}=40)\end{array}$ & p value \\
\hline $\begin{array}{l}\text { Meconium stained } \\
\text { liquor }\end{array}$ & $5(12.5 \%)$ & $3(7.5 \%)$ & $0.713^{\$}$ \\
\hline NICU admission & $7(17.5 \%)$ & $5(12.5 \%)$ & $0.758^{\$}$ \\
\hline $\begin{array}{l}\text { Prematurity and } \\
\text { LBW }\end{array}$ & 4 & 4 & \\
\hline $\begin{array}{l}\text { Meconium } \\
\text { aspiration }\end{array}$ & 1 & - & \\
\hline Respiratory distress & 2 & 1 & \\
\hline \# unpaired t test \#\# Chi square test \$ Fisher's exact test \\
\hline
\end{tabular}

\section{DISCUSSION}

Several studies are conducted to compare misoprostol and PGE2 gel for induction of labor at term but few studies are available which study their comparison in PROM after 34 weeks of gestation. In this present study, we have evaluating whether misoprostol can be used instead of PGE2 gel for induction of labor in prelabor rupture of membranes. Recommended oral dose of $50 \mathrm{mcg}$ misoprostol was for induction in our study which was safe for both mother and fetus. ${ }^{7,8}$ The intervention to induction interval was significantly slow in misoprostol group ( $\mathrm{p}$ - 0.004), these finding was corroborated. ${ }^{7}$ Induction to delivery interval in present study was not statistically significant $(\mathrm{p}-0.628)$ which was similar to other studies. ${ }^{9,10}$ But studies by Abraham et al, Frohn et al and Oza A et al showed significantly less induction to delivery interval in misoprostol group. ${ }^{11-13}$ 
In present study vaginal deliveries were $87 \%$ versus $82 \%$ in misoprostol and PGE2 group respectively other authors like Gupta A et al (78\% versus $88 \%)$, Chaudhary et al $(92.39 \%$ versus $84.70 \%)$ and Oza A et al $(68 \%$ versus $80 \%$ ) had variable vaginal deliveries rate but without any significant difference. ${ }^{9,10,13}$ Oxytocin requirement for induction or augmentation of labor was significantly less in misoprostol group (p - 0.039) which was also noticed by Pooja et al and Nagpal et al. ${ }^{14,15}$ Studies revealed cesarean section rate lower in misoprostol group then PGE2 group which was similar to our study $12.5 \%$ versus $17 \%$ but not statistically significant ( $\mathrm{p}$ - 0.758), whereas Oza A et al and Gupta A et al revealed contrary findings..$^{7,10,13,9}$ Zang $\mathrm{Y}$ e $\mathrm{t}$ al also reported no significant difference in rate of cesarean delivery (odds ratio (OR) $0.90 ; 95 \%$ CI $0.44-1.85$ ) in both the groups. ${ }^{16}$ Women receiving misoprostol had a significantly higher rate of tachysystole than those receiving PGE2 gel (OR 4.84; 95\% CI 2.46-9.54) but in our study there was no significant difference probably due to low dose of misoprostol along with judicious use and monitoring of women while on labor induction. ${ }^{16}$ The indications of caesarean sections were similar in both groups though fetal distress was more in misoprostol group. Meconium stained liquor was not significantly more in misoprostol group in present study while other studies revealed increased meconium stained liquor this may be due to low dose of misoprostol and its judicious use while labor induction. ${ }^{7}$ As per Zang $\mathrm{Y}$ et al rate of neonatal intensive care unit admission (OR 0.89; 95\% CI 0.57-1.38) was similar in both groups which was similar to present study. ${ }^{16}$ There was no major complication in either group with regards to maternal and perinatal effects. Active management of PROM women has fewer chances of chorioamnionitis, neonatal infection and morbidity and thus less hospital stay. ${ }^{3,17}$

\section{CONCLUSION}

With almost $5-10 \%$ of women in obstetrics practice present with PROM low dose oral misoprostol as an inducing agent was found to be as effective as PGE2 gel in achieving vaginal deliveries with less need of oxytocin for induction or augmentation of labor without increasing caesarean section rate, maternal or neonatal morbidity and with additional benefit of ease of administration, storage of drug and cost effectiveness provided labor rooms are equipped with monitoring facilities.

Funding: No funding sources Conflict of interest: None declared

Ethical approval: The study was approved by the Institutional Ethics Committee

\section{REFERENCES}

1. Royal college of obstetricians and gynecologists (rcog). induction of labour, evidence-based clinical guideline number 9. rcog clinical effectiveness support unit. London: RCOG press; 2001.
2. Amjad N, Rasheed F, Imran T. Comparison of the response of oxytocin versus prostaglandin E2 vaginal pessary for labour induction in pre labour rupture of membranes. Annals. 2009;15:80-4.

3. Hannah ME, Ohlsson A, Farine D, Hewson SA, Hodnett ED, Myhr TL, et al. Induction of labour compared with expectant management for pre labour rupture of membranes at term PROM study group. N Engl J Med. 1996;334:1005-10.

4. Jazayeri A, Galan H. Premature rupture of membranes; 2006. Available from: URL: http://www.emedicine.com/med/topic3246.htm.

5. Kelly AJ, Kavanagh J, Thomas J. Vaginal prostaglandin (PGE2 and PGF2a) for induction of labor at term. Cocharane Database Syst Rev. 2003; 4:CD003101.

6. Hannah ME. Induction of labor compared with expectant management for pre labour rupture of the membranes at term. New England $\mathbf{J}$ Med. 1996;334:1005-10.

7. Alfirevic Z, Aflaifel N, Weeks A. Oral misoprostol of induction of labour (Review). Cochrane Database of Systematic Reviews 2014;6:CD001338.

8. Weeks A, Alfirevic Z, Faundes A, Hofmeyr GJ. Misoprostol for induction of labor with a live fetus. Int J of Gynaecol Obstet. 2007;99:5194-7.

9. Gupta A, Kumari S. Prostaglandin E1 tablet versus prostaglandin E2 gel for induction of labor in prelabor rupture of membrane at term. International journal of enhanced research in medicines and dental care. $2015 ; 2(6): 1-7$.

10. Chaudhary S, Mitra SN, Benerjee PK, Biswas PK, Bhattacharya S. Comparison of vaginal misoprostol tablets and prostaglandin E2 gel for the induction of labor in premature rupture of membrane at term: A randomized comparative trial. J Obstet Gynecol Res. 2011;37:1564-71.

11. Abraham C, Meirowitz N, Kohn N. Labor induction for premature rupture of membranes using vaginal misoprostol versus dinoprostone vaginal insert. Am J Perinatol. 2014;31(3):181-6.

12. Frohn WE, Simmons S, Carlan SJ. Prostaglandin E2 gel versus misoprostol for cervical ripening in patients with premature rupture of membranes after 34 weeks. Obstet Gynecol. 2002;99:206-10.

13. Oza A, Shah JM, Mewada B, Thaker R. A comparative study between PGE1 and PGE2 for induction of labour in premature rupture of membrane at term. Int $\mathbf{J}$ Reprod Contracept Obstet Gynecol. 2016;5:202-5

14. Deodhar P, Rai S. Comparative study of misoprostol versus dinoprostone for induction of labour. Ind Med Gaz. 2013:2:454-7.

15. Nagpal MB, Raghunandan C, Saili A. Oral misoprostol versus intracervical prostaglandin E2 gel for active active management of premature rupture of membranes at term. Int $\mathbf{J}$ Gynaecol Obstet. 2009;106(1):23-6.

16. Zhang Y, Wang J, Yu Y, Xie C. Misoprostol versus prostaglandin E2 gel for labor induction in premature 
rupture of membranes after 34 weeks of pregnancy. Int J Gynaecol Obstet. 2015;130(3):214-8.

17. Shah K, Doshi H. Premature Rupture of Membrane at Term: Early Induction Versus Expectant Management. J Obstet Gynaecol India. 2012;62(2):172-5.
Cite this article as: Mane JD, Singh AK. Can prostaglandin E1 (Misoprostol) be an alternative to prostaglandin E2 (PGE2) for induction of labor in prelabor rupture of membranes (PROM) after 34 weeks period of gestation. Int J Reprod Contracept Obstet Gynecol 2017;6:4297-4301. 